\title{
Molecular Basis of Androgen Resistance in a Family with a Qualitative Abnormality of the Androgen Receptor and Responsive to High-Dose Androgen Therapy
}

\author{
Michael J. McPhaul, Marco Marcelli, Wayne D. Tilley, James E. Griffin, Rosario F. Isidro-Gutierrez, and Jean D. Wilson \\ Department of Internal Medicine, University of Texas Southwestern Medical Center at Dallas, Dallas, Texas 75235-8857; \\ and Department of Obstetrics and Gynecology, College of Medicine, University of the Philippines, Manila, Philippines
}

\begin{abstract}
We have examined the nature of the mutant androgen receptor in a family with a severe defect in virilization associated with a qualitative defect in receptor function. The androgen receptor gene in this family contains two structural alterations: a single nucleotide substitution at position 2444 in exon 5 (adenosine $\rightarrow$ guanosine) that converts tyrosine 761 to a cysteine residue and a shortened glutamine homopolymeric segment in exon 1 that encodes 12 rather than the usual 20-22 glutamines. A family study was performed using polymerase chain reaction amplification of the glutamine-rich segment, and it was shown that the sister of the proband does not carry the mutant allele. The effects of these two mutations on the function of the androgen receptor were studied by introducing the changes, individually and in combination, into cDNAs encoding the normal human androgen receptor and analyzing the receptor protein produced after transfection of the cDNAs into eukaryotic cells. The presence of a cysteine residue at position 761 causes rapid dissociation of dihydrotestosterone from the receptor protein. Marked thermolability of the transfected receptor protein, however, was demonstrable only upon introduction of an androgen receptor cDNA containing both the partial deletion of the glutamine homopolymeric segment and a cysteine residue at position 761 . Likewise, the ability of the receptor to stimulate a reporter gene is strikingly diminished only when both alterations are present, suggesting that the shortened glutamine homopolymeric segment amplifies the impairment of receptor function caused by the tyrosine to cysteine substitution. (J. Clin. Invest. 1991. 87:1413-1421.) Key words: androgen resistance $\bullet$ androgen receptor $\cdot$ mutation
\end{abstract}

\section{Introduction}

Defects in the androgen receptor are X-linked disorders that cause a spectrum of abnormalities in affected men that vary in severity from phenotypic women with the syndrome of complete testicular feminization to men with mild defects in virilization (1). At the functional level these defects can be grouped into four broad categories: absent binding, qualitative defects in receptor function, deficient amounts of apparently normal

Address reprint requests to Dr. McPhaul, Department of Internal Medicine, University of Texas Southwestern Medical Center at Dallas, 5323 Harry Hines Boulevard, Dallas, TX 75235-8857.

Received for publication 13 September 1990 and in revised form 21 November 1990.

J. Clin. Invest.

(c) The American Society for Clinical Investigation, Inc.

0021-9738/91/04/1413/09 \$2.00

Volume 87, April 1991, 1413-1421 receptor, and receptor positive resistance, a category in which the endocrine, phenotypic, and genetic features are compatible with a receptor abnormality but no functional abnormality has been identified (1). The cloning of the cDNA that encodes the androgen receptor has made possible the delineation of the molecular nature of the defects in several such patients (2-6). In the studies reported to date, attention has focused on patients with the syndrome of complete testicular feminization, most of whom have absent binding. In this group of patients, known defects include major gene rearrangements (6), premature termination codons $(2,3)$, and point mutations that profoundly impair receptor function $(4,5)$.

We have previously described a family with androgen resistance associated with profound hypospadias but considerable virilization after the time of expected puberty (7). The androgen receptor expressed in cultured skin fibroblasts from an affected member of this pedigree was normal in amount and exhibited only mild qualitative abnormalities. More importantly, the functional defect in the propositus could be largely overcome by high-dose androgen therapy. These findings indicate that the defect in this family only partially impairs receptor function. In the current study we report that the gene encoding the androgen receptor in this family contains two abnormalities: a shortened glutamine homopolymeric region in exon 1 and a point mutation in exon 5 that causes an amino acid substitution at position 761 . We have taken advantage of the shortened glutamine homopolymeric region to perform family studies and document that the sister of the propositus does not carry the mutant gene. In addition, we have constructed mutant androgen receptor cDNAs that contain each of the mutations, alone and in combination, expressed these cDNAs in transfected cells, and characterized the receptor function. Our results indicate that the two changes interact to cause the thermolability and accelerated ligand dissociation rates previously described in cultured skin fibroblasts.

\section{Methods}

Cell culture and nucleic acid preparation. DNA was prepared as described (2) from confluent genital skin fibroblasts cultured from three patients. Strains 787 and 712 were from the previously described proband (III-4) and his sister (III-3), respectively (7). In addition, scrotal skin fibroblasts (strain 810) from an uncle (II-5) of the proband were studied. The androgen receptor in II-5 was thermolabile (68\% decrease at $41^{\circ} \mathrm{C}$ in $90 \mathrm{~min}$ ) and exhibited an accelerated dissociation rate with $\left[{ }^{3} \mathrm{H}\right]$ dihydrotestosterone $(90 \%$ dissociation of ligand at $1 \mathrm{~h}$, compared with 35\% dissociation in the normal control), findings similar to those previously reported for the proband (7). For the genetic analysis of other family members, blood samples were shipped from Manila to Dallas, and DNA was prepared from white blood cell pellets. RNA was prepared from cultures of genital skin fibroblasts (strains 704 and 787) at confluence; the cells were harvested and homogenized in $4.5 \mathrm{M}$ 
guanidinium isothiocyanate, and RNA was purified by centrifugation through a cushion of $5.7 \mathrm{M}$ cesium chloride (8).

Amplification of the androgen receptor gene coding exons. The coding exons of the androgen receptor gene were amplified using oligonucleotides derived from the segments flanking each exon (3) as primers for the polymerase chain reaction (9). Exon 1, which spans the first 1,900 nucleotides of the androgen receptor open reading frame, was analyzed using five overlapping pairs of oligonucleotides (3). Each amplification was performed for 35 cycles, (annealing and extension for 90 $\mathrm{s}$ at $68^{\circ} \mathrm{C}$ and denaturation for $45 \mathrm{~s}$ at $95^{\circ} \mathrm{C}$ ). The glycine homopolymeric region of exon 1 was difficult to amplify with the polymerase chain reaction. As reported (3), this region of the androgen receptor gene could only be amplified using $>70$ amplification cycles. Even after prolonged amplification sequence analysis showed consistently truncation of the glycine-rich region to a segment encoding eight repeats of the triplet GGC. For this reason, an alternative method of sequence was employed for this segment. Namely, a genomic library was constructed from the DNA of patient 787: $600 \mu \mathrm{g}$ of genomic DNA was cut to completion with the restriction endonuclease EcoRI and electrophoresed in a $0.8 \%$ agarose gel. The DNA fragments between 9 and $23 \mathrm{~kb}$ were purified and ligated in the cloning vector EMBL4 (10). The resulting library, which had a complexity of $5 \times 10^{5}$ recombinants, was screened with a 1-kb restriction endonuclease fragment derived from the $5^{\prime}$ flanking segment of the human androgen receptor gene. One positive clone was isolated and purified. The fragment containing the glycine-rich region was subcloned into the sequencing vector M13 and sequenced with dideoxy sequencing (11).

Nucleotide sequencing. Each oligonucleotide used for the amplification of the human androgen receptor contains an artificial EcoRI restriction site at its $5^{\prime}$ terminus. After amplification, the resulting band was purified and subcloned into the sequencing vector M13 previously digested with EcoRI. Templates were sequenced using the dideoxy sequencing method of Sanger et al. (11). Each deviation from the normal androgen receptor sequence (12) was confirmed at least twice in templates derived from different amplification reactions.

Site-directed mutagenesis. The deletion of the glutamine-rich region detected from the sequencing of exon 1 of patient Q787 was inserted into the expression vector CMV3. Our original expression plasmid CMVhAR3.1 (12), which contains the normal human androgen receptor cDNA subcloned as an EcoRI restriction endonuclease fragment in the expression vector CMV-3, contains unique cleavage sites for the restriction endonucleases AflII and NarI at nucleotide positions 672 and 313 , respectively (12). These restriction endonuclease cleavage sites flank the position of the glutamine homopolymeric segment. To create truncation of the glutamine rich segment present in the androgen receptor gene of patient $\mathrm{Q} 787$, the fragment derived from the amplification of segment I-2 of exon 1 (3) of the androgen receptor of patient Q787 was cut with the restriction endonucleases AflII and Narl. The resulting fragment, encoding only 12 glutamines, was ligated into the plasmid CMVAR 3.1 (12) digested with Narl and AflII. The structure of this plasmid was confirmed to contain a glutamine homopolymeric segment 12 residues long (designated CMVhAR GIn-12) by DNA sequence analysis.

The second mutation, consisting of an adenosine $\rightarrow$ guanosine transition at nucleotide 2444 was incorporated as shown below into the two oligonucleotides that span nucleotide 2431 to 2459 of the androgen receptor cDNA (12):

\section{Mut Tyr $\rightarrow$ Cys s: TCCAGGATGCTCT $\underline{\text { CTTCGCCCCTGAT }}$}

\section{Mut Tyr $\rightarrow$ Cys as: ATCAGGGGCGAAGCAGAGCATCCT-GCA}

These oligonucleotides were used in combination with other oligonucleotides to incorporate the desired nucleotide substitution (underlined) into the androgen receptor cDNA sequence. Oligo MUTTyr $\rightarrow$ Cys " $s$ " and a second oligonucleotide derived from the segment 3 ' to the coding segment of the androgen receptor cDNA [oligonucleotide $710 \mathrm{Xba}$ : ACTCTAGAAGAGGAGTAGTGCAGAGTTATACCA (3)] were used to amplify a $1-\mu \mathrm{g}$ sample of the androgen receptor
cDNA. This reaction results in the synthesis of the $3^{\prime}$ terminus of the androgen receptor containing the desired mutation and an artificial XbaI restriction site flanking its carboxy terminus (reaction I). In a similar fashion, oligo MUT-Tyr $\rightarrow$ Cys "as" and oligonucleotide mutH3 [GGAGATGAAGCTTCTGGGTGTCACT (3)] were used to amplify a $1-\mu \mathrm{g}$ sample of human androgen receptor cDNA (reaction II). The products of reactions I and II were purified by electrophoresis, and the two resulting bands, which contain a 25-nucleotide region of homology, were annealed to each other and amplified using the oligonucleotides $710 \mathrm{XbaI}$ and oligonucleotide mutH $_{3} \mathrm{HindIII}$ as primers. The resulting band was digested with the restriction endonucleases HindIII and XbaI and purified by agarose gel electrophoresis. Since the androgen receptor cDNA contains only one internal HindIII cleavage site and the expression vector $\mathrm{CMV} 3$ contains only a single $\mathrm{XbaI}$ restriction site flanking the carboxy terminus of the inserted cDNA, it was possible to remove the carboxy terminus from the normal androgen receptor contained in plasmid CMV3.1 and from CMVAR Gln-12 by digestion with the restriction endonuclease HindIII and $\mathrm{XbaI}$ and to replace these fragments with the DNA fragment containing the mutation in exon 5 of the androgen receptor of patient Q787. The plasmid designations and position of mutations are shown in Fig. 1. All four plasmids were shown by nucleotide sequence analysis to contain only the indicated mutations.

RNA protection assay. Androgen receptor $\mathrm{mRNA}$ levels were determined as described previously $(2,3)$. In brief, samples of total RNA were hybridized to a single-stranded radiolabeled RNA probe derived from nucleotides 1850 to 2563 of the androgen receptor cDNA. After hybridization and digestion with $S_{1}$ nuclease, the reaction products were analyzed by electrophoresis on a $6 \%$ polyacrylamide gel containing $8 \mathrm{M}$ urea and visualized by autoradiography. Levels of androgen receptor mRNA were estimated by comparison with samples containing mRNA from normal fibroblasts or varying amounts of synthetic androgen receptor mRNA.
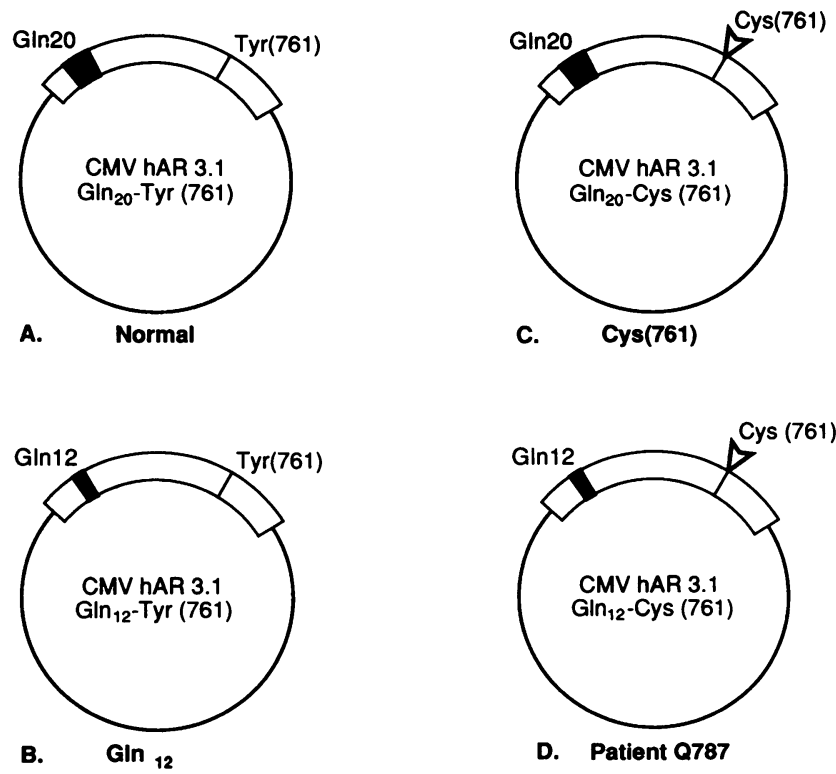

Figure 1. Schematic structure of the expression plasmids encoding the normal and mutant androgen receptors. $(A)$ Normal androgen receptor, which contains 20 glutamine residues in the homopolymeric domain and a tyrosine residue at amino acid 761. (B) Gln 12 contains 12 glutamine residues and a tyrosine at position 761. (C) Cys 761. This plasmid contains 20 glutamine residues in the homopolymeric segment and a cysteine residue at position 761. (D) Diagram analogous to the androgen receptor predicted for patient 787 and contains 12 glutamine residues and a cysteine residue at position 761 . This plasmid is designated Q787. 
Cell transfection. Both transient and stable transfection protocols were employed to analyze the physical properties of the mutant receptors in cell culture. COS cells were transiently transfected using the calcium phosphate precipitation method (13). On day 0 , cells were plated at a density of $10^{6}$ cells per $10 \mathrm{~cm}$ dish; $12 \mathrm{~h}$ later a calcium phosphate precipitate containing DNA was added to the cultures. After incubation for an additional $5 \mathrm{~h}$ at $37^{\circ} \mathrm{C}$, the cells were osmotically shocked with $15 \%$ glycerol for $3 \mathrm{~min}$, fresh medium was added, and the incubation was continued for $48 \mathrm{~h}$ at which time soluble androgen receptor was prepared (see below).

Stable transfected cell lines were established in Chinese hamster ovary $(\mathrm{CHO})^{1}$ cells by cotransfection of $1 \mu \mathrm{g}$ of the plasmid pSV2neo (14) and $10 \mu \mathrm{g}$ of the expression plasmid encoding the normal or mutant androgen receptor, followed by selection with the antibiotic G418 at a final concentration of $400 \mu \mathrm{g} / \mathrm{ml}$ (Gibco Laboratories, Grand Island, NY). The cell populations analyzed represent pools of $\sim 50-200$ independent G418-resistant colonies.

Monolayer binding assays. Binding assays were performed on monolayer cultures of $\mathrm{CHO}$ cells stably transfected with cDNA clones encoding the normal or mutant androgen receptor proteins (15). [17 $\alpha$-methyl $-{ }^{3} \mathrm{H}$ ]mibolerone (sp act $87 \mathrm{Ci} / \mathrm{mmol}$ ) was obtained from $\mathrm{New}$ England Nuclear, Boston, MA, and $\left[1,2,6,7-{ }^{3} \mathrm{H}\right] 5 \alpha$-dihydrotestosterone (sp act $128 \mathrm{Ci} / \mathrm{mmol}$ ) was obtained from Amersham Corp., Arlington Heights, IL. For saturation analysis, cultures of $\mathrm{CHO}$ cells grown in $6 \mathrm{~cm}$ diam wells were incubated with medium containing $\left[1,2,6,7-{ }^{3} \mathrm{H}\right] 5 \alpha$-dihydrotestosterone $(0.5-3 \mathrm{nM})$ in the presence or absence of a 500 -fold excess of unlabeled $5 \alpha$-dihydrotestosterone. After incubation for $1 \mathrm{~h}$ at $37^{\circ} \mathrm{C}$, the cultures were rinsed and harvested by trypsinization. The resulting cell pellets were dispersed in distilled water and sonicated. Portions of the cell homogenate were assayed for protein and for tritiated steroid content.

The effect of temperature on the stability of the androgen receptor expressed in the transfected CHO cells was assessed as described (7). Monolayer cultures were incubated with medium containing $2 \mathrm{nM}$ $\left[{ }^{3} \mathrm{H}\right]$ mibolerone prewarmed to 30 or $40^{\circ} \mathrm{C}$. After a 45 -min incubation at the two temperatures the cells were harvested as above, and the levels of specific dihydrotestosterone binding were determined.

Assays of ligand dissociation in monolayer cultures. The rate of $\left[{ }^{3} \mathrm{H}\right]$ mibolerone dissociation was examined in monolayer cultures of transfected CHO cells using a protocol developed for analysis of cultured genital skin fibroblasts (7). Parallel cultures were incubated with $2 \mathrm{nM}\left[{ }^{3} \mathrm{H}\right]$ mibolerone for $1 \mathrm{~h}$ at $37^{\circ} \mathrm{C}$ in the presence or absence of excess unlabeled mibolerone. At time zero the medium containing the radioactive ligand was removed and replaced with medium containing $2 \mathrm{nM}$ unlabeled mibolerone, and the incubation was continued at $37^{\circ} \mathrm{C}$ for $1-5 \mathrm{~h}$. The percentage of specific mibolerone binding remaining at each time point was compared to the level of specific mibolerone binding in samples to which no competitor steroid had been added. Cycloheximide ( $500 \mu \mathrm{mol} / \mathrm{liter}$ ) was included in all assays to minimize new androgen receptor synthesis.

Preparation and analysis of cytosolic androgen receptor produced in transfected COS cells. The physical properties of the androgen receptor proteins predicted from the normal and mutant androgen receptor cDNA sequences were assessed by studying the soluble androgen receptor protein produced in transiently transfected COS cells. Soluble receptor was prepared by scraping the cells in a minimum volume of ice-cold TEGM buffer (10 mM Tris $\cdot \mathrm{HCl} / 1 \mathrm{mM}$ EDTA/10\%[vol/vol] glycerol/1 mM 2-mercaptoethanol/10 mM sodium molybdate, $\mathrm{pH}$ 7.2), disruption of the cells by passage through a 21 -gauge needle, and centrifugation at $100,000 \mathrm{~g}$ for $30 \mathrm{~min}$. The androgen receptor was incubated at $4^{\circ} \mathrm{C}$ for $4 \mathrm{~h}$ with $3 \mathrm{mM}\left[{ }^{3} \mathrm{H}\right]$ dihydrotestosterone in the presence or absence of a 200 -fold excess of unlabeled dihydrotestosterone. After the labeling period, the fractions were incubated at $37^{\circ} \mathrm{C}$,

1. Abbreviations used in this paper: CAT, chloramphenicol acetyl transferase; $\mathrm{CHO}$, Chinese hamster ovary (cells); MMTV, mouse mammary tumor virus. and specific dihydrotestosterone binding at 0-, 0.5-, 1-, and 3-h intervals was assayed by removal of aliquots and absorption of free dihydrotestosterone with dextran-coated charcoal (12). Specific binding was calculated as the difference between total and nonspecific binding.

Cotransfection assays. The capacity of the normal and mutant receptor to activate gene transcription was assayed by cotransfection of the reporter gene MMTV-CAT (16) and a plasmid encoding the normal or mutant androgen receptor into CV1 cells (3). CV1 cells were transfected on day 1 with $10 \mu \mathrm{g}$ of MMTV-CAT and a variable mass of androgen receptor expression plasmid $(0,50,200$, or $1,000 \mathrm{ng})$. For quantitative comparisons of the relative activity of the normal and mutant androgen receptor cDNAs, cell preparations were transfected in quadruplicate with $200 \mathrm{ng}$ of each receptor CDNA and $10 \mu \mathrm{g}$ of the MMTV CAT reporter plasmid. $5 \mathrm{~h}$ after transfection, the cells were osmotically shocked for 3 min with $15 \%$ glycerol in Hepes-buffered saline, $\mathrm{pH} 7.05$, and fresh medium was added. $24 \mathrm{~h}$ after transfection, the medium was replaced with medium containing varying concentrations of $5 \alpha$-dihydrotestosterone or mibolerone. Incubations were continued in medium containing steroid for a total of $48 \mathrm{~h}$ with medium changes after $24 \mathrm{~h}$. Cell cultures were harvested and assayed as described (17).

\section{Results}

The androgen receptor gene of patient $Q 787$ contains two alterations. Fibroblasts cultured from the proband express normal amounts of a qualitatively abnormal androgen receptor protein that displayed thermolability and an accelerated rate of ligand dissociation (7). Subsequent studies on a second affected family member (II-5) revealed similar abnormalities. To determine the molecular basis of the androgen resistance in this family (Q787) we employed the polymerase chain reaction to amplify individual segments of the androgen receptor gene. This analysis revealed two differences within the coding segment of the androgen receptor gene. The first is a shortening of the glutamine homopolymeric segment in exon 1 . Thus, in patient Q787 this region encodes only 12 glutamine residues, while most individuals contain an average of 20-22 residues. The second alteration is a single nucleotide change at position 2444 in exon 5 that converts the triplet T $\underline{A C}$ to the triplet TGC and results in a tyrosine to cysteine substitution at amino acid residue 761 . The positions of these two mutations in the androgen receptor coding sequence are shown schematically in Fig. 2. The identification of two separate alterations in the andro-

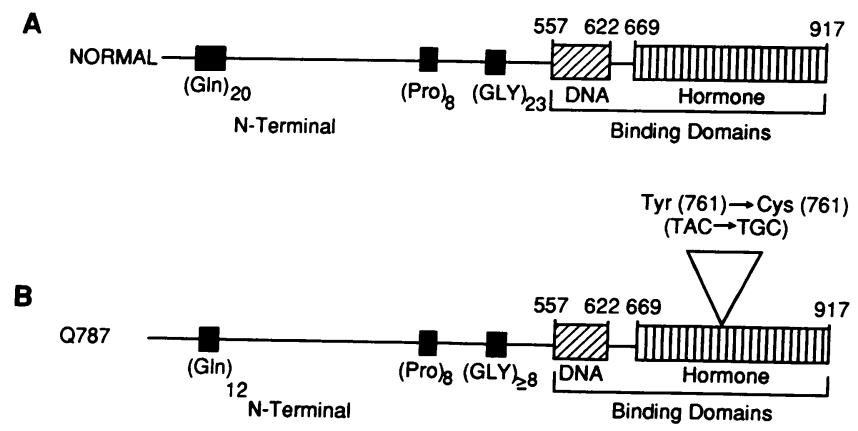

Figure 2. Schematic structure of the mutations detected in patient Q787. $(A)$ Schematic structure of the normal human androgen receptor. $(B)$ Position of the changes detected in the androgen receptor gene of patient Q787. In this patient, the glutamine homopolymeric segment contains 12 residues and a tyrosine to cysteine substitution in exon 5 . The length of the glycine homopolymeric segment is indicated as a minimum estimate owing to artificial truncations that occur within this segment during amplification (3). 
gen receptor gene raised two questions: first, whether the shortened homopolymeric region could be utilized as a polymorphism to analyze the inheritance of the mutant gene in this family; and second, whether one or both of these mutations is responsible for defective receptor function in this family.

To examine the first issue we analyzed genomic DNA from affected and unaffected individuals within the family of the proband (patient III-4 Q787) (Fig. 3). To this end we measured the substitution mutation in exon 5 in one additional family member (II-5), the mother of the propositus (II-2) and the sister of the propositus (III-3). In addition, segment I-2 (3) in the amino terminus of the androgen receptor gene that contains the glutamine homopolymeric segment was analyzed in eight family members and three spouses. Both mutations are present within the androgen receptor gene of the two affected individuals. By contrast, neither the shortened homopolymeric segment nor the $\mathrm{Tyr} \rightarrow$ Cys substitution was detected in normal men within this family. This analysis also reveals the carrier status of females in this family. Thus, the mother, grandmother, and aunts of the proband are confirmed as heterozygous carriers, while the sister (III-3) of patient Q787 does not carry the mutant allele.

Androgen receptor $m R N A$ levels are not diminished in fibroblasts established from patient Q787. Androgen receptor mRNA levels are reduced in some patients with complete androgen resistance (3). For this reason, we examined the levels of androgen receptor mRNA present in the fibroblasts of patient Q787 using a solution hybridization assay. The results of this study indicate that androgen receptor mRNA levels are similar to those in a normal control fibroblast strain, 704 (results not shown).

The rapid dissociation of dihydrotestosterone is caused by the tyrosine to cysteine substitution. To characterize androgen binding in monolayer cell cultures, we established stable cell lines by introducing the expression plasmid CMV encoding normal or mutant androgen receptor $\mathrm{CDNAs}$ and the plasmid pSV2neo into CHO cells. Pools of G418-resistant CHO cells were analyzed in monolayer culture to examine the rate of dissociation of ligand from the receptor at $37^{\circ}$. As shown in Fig. 4 , in cells transfected with plasmids that contain the tyro- sine to cysteine substitution (Cys 761 or Q787) dissociation of mibolerone from the receptor is accelerated, as compared to the cells transfected with the normal androgen receptor cDNA (3.1). In contrast, cells transfected with the Gln 12 plasmid showed no difference compared to the normal androgen receptor (data not shown). The dissociation rate of ligand from the receptor was more rapid in cells transfected with the Q787 plasmid that contains both mutations than in cells transfected with the cDNA that contains only the tyrosine to cysteine mutation. While this difference between the receptors encoded by the Cys 761 and Q787 plasmids was detectable at both 37 and $30^{\circ} \mathrm{C}$, the abnormal dissociation rate was more pronounced in the Cys 761 receptor at $37^{\circ} \mathrm{C}$. These changes in dissociation rate were not accompanied by an appreciable change in the apparent $K_{\mathrm{d}}$ of $5 \alpha$-dihydrotestosterone binding, as shown in Table I.

The two mutations in the androgen receptor gene of patient Q787 lead to the synthesis of a thermolabile androgen receptor protein in transfected cells. The androgen receptor produced in patient Q787 was thermolabile in cultured fibroblasts (7). To examine the effects of the two mutations on the thermostability of the expressed androgen receptor in transfected cells, we analyzed $\mathrm{CHO}$ cells stably transfected with the four expression plasmids in monolayer binding assays at 30 and $40^{\circ} \mathrm{C}$ (Fig. 5). The levels of specific androgen binding in $\mathrm{CHO}$ cells transfected with the cDNA encoding the normal androgen receptor were similar at 30 and $40^{\circ} \mathrm{C}$. Likewise, cells transfected with the Gln 12 (data not shown) or Cys 761 expression plasmids also exhibited similar levels of binding at the two temperatures. By contrast, the androgen receptor in cells transfected with the Q787 expression plasmid cDNA exhibits marked thermolability.

The stability of the mutant androgen receptor proteins were also studied in extracts of COS cells after transfection. Cytosolic receptor from transiently transfected COS cells was labeled with a saturating concentration of $\left[{ }^{3} \mathrm{H}\right]$ dihydrotestosterone at $4^{\circ} \mathrm{C}$, and the stability of the receptor proteins was assessed by incubation at $37^{\circ} \mathrm{C}$ for varying periods. After treatment with dextran-coated charcoal to remove the unbound steroid, the quantity of specific $\left[{ }^{3} \mathrm{H}\right]$ dihydrotestosterone

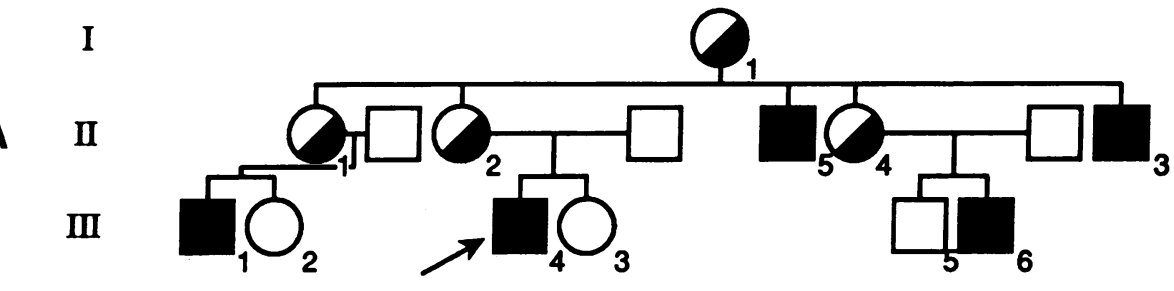

B

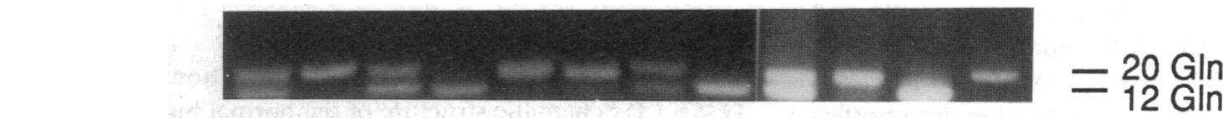

C Tyr (761)

Cys (761)
Figure 3. Genetic analysis of mutations in the family of patient Q787. (A) Partial pedigree of patient Q787 (indicated by the arrow). The half-filled circles represent obligate heterozygous carriers on the basis that each has had one or more affected children. The filled squares represent affected hemizygous males. $(B)$ Polymerase chain reaction analysis of region I-2 (3) of the human androgen receptor gene. $(C)$ Analysis of the nucleotide residue at position 2444 (12) in selected patients within the pedigree. The designation of family members is in accord with the previously reported family tree (7). ND, not done. 


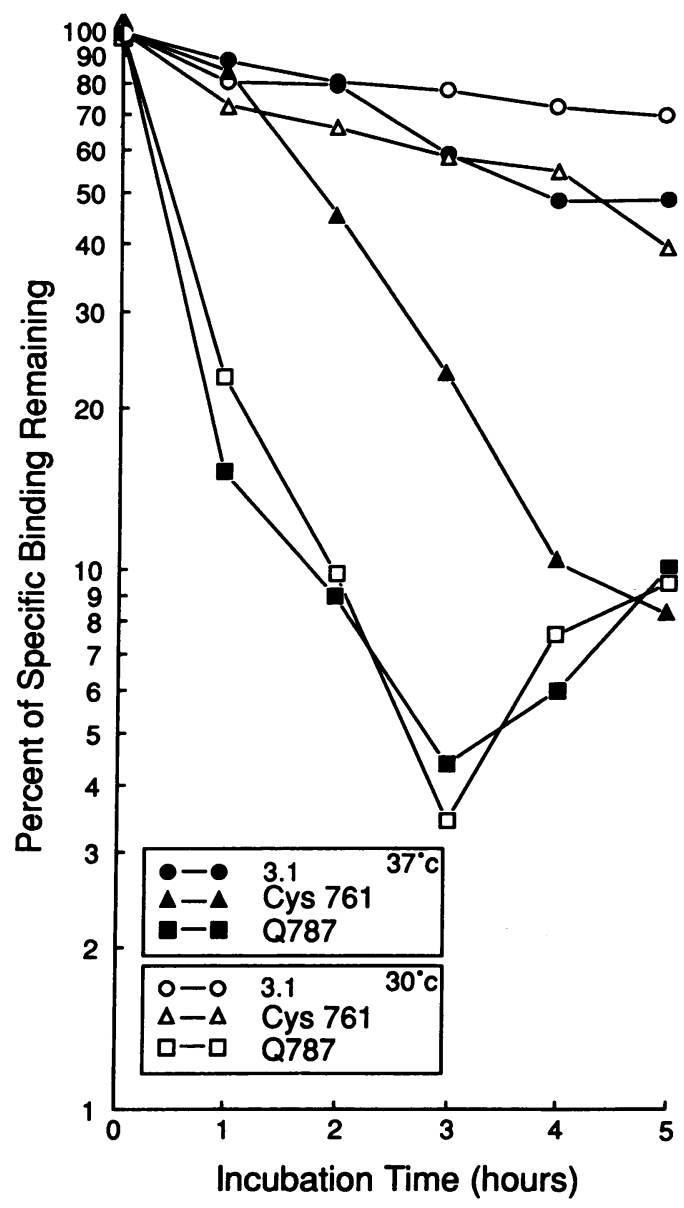

Figure 4. The tyrosine to cysteine amino acid substitution at residue 761 causes mibolerone to dissociate more rapidly from the androgen receptor protein. The rate of dissociation of $\left[{ }^{3} \mathrm{H}\right]$ mibolerone from CHO cells stably transfected with cDNAs encoding normal or mutant androgen receptors was examined in cell monolayers. Parallel cultures of cells were incubated with $2 \mathrm{nM}\left[{ }^{3} \mathrm{H}\right]$ mibolerone for $1 \mathrm{~h}$ at 37 or $30^{\circ} \mathrm{C}$. At time zero the radioactive mibolerone was removed and replaced with medium containing unlabeled competitor mibolerone. The amount of specific mibolerone binding remaining in the cell cultures incubated with excess unlabeled mibolerone is compared to cultures to which no unlabeled steroid had been added. In separate experiments, we established that ligand dissociation from the receptor expressed in CHO cells transfected with the Gln 12 plasmid was indistinguishable from that expressed in cells transfected with the normal androgen receptor cDNA.

binding was determined (Fig. $6 \mathrm{~A}$ ). Truncation of the glutamine segment has no appreciable effect on the thermal stability of the receptor protein, whereas the tyrosine to cysteine substitution at residue 761 causes some thermal lability at $37^{\circ} \mathrm{C}$ after prolonged incubation. The presence of both mutations in the same androgen receptor molecule, however, effects a marked change in the stability of the androgen receptor. This decline of specific androgen binding at $37^{\circ} \mathrm{C}$ was not accompanied by appreciable changes in the level or apparent integrity of immunoreactive androgen receptor as determined by Western analysis (Fig. 6 B).

Truncations of the glutamine homopolymeric segment alter the functional capacity of mutant androgen receptors. The functional capacities of androgen receptors containing the muta-
Table I. Binding Affinities of the Normal and Mutant Androgen Receptors as Determined in Stably Transfected Chinese Hamster Ovary Cells

\begin{tabular}{ll}
\hline & Apparent $K_{\mathrm{d}}$ \\
\hline Normal & 0.16 \\
Gln 12 & 0.17 \\
Cys 761 & 0.3 \\
Q787 & $0.47^{*}$
\end{tabular}

The apparent $K_{\mathrm{d}}$ of binding of $\left[^{3} \mathrm{H}\right] 5 \alpha$-dihydrotestosterone was determined by Scatchard analysis of data obtained using a monolayer binding assay to detect the level of specific androgen binding in $\mathrm{CHO}$ cells stably transfected with the expression plasmids and psv2neo (see text).

* The data for the cells transfected with the Q787 plasmid were derived from binding assays performed at $30^{\circ} \mathrm{C}$ owing to the thermolability of the receptor protein.

tions identified in the androgen receptor gene of patient Q787 were assayed by the cotransfection of CV 1 cells with expression plasmids encoding normal or mutant androgen receptors and a reporter gene (chloramphenicol acetyl transferase, CAT) controlled by the mouse mammary tumor virus long terminal repeat (MMTV-LTR) $(3,16)$ (Fig. 7). Truncation of the glutamine homopolymeric segment (Gln 12) alone does not alter receptor function, as cells transfected in parallel with the

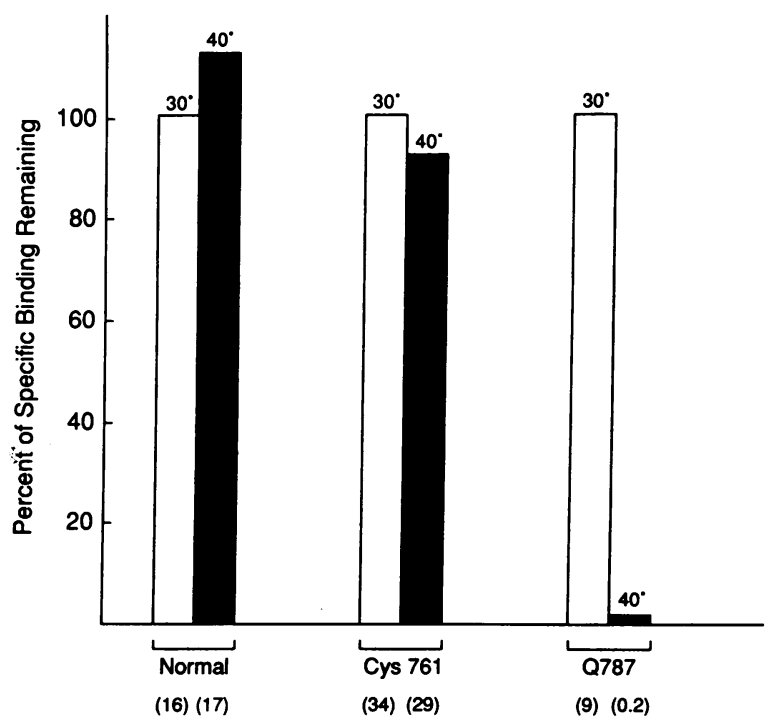

Figure 5. Stability of normal and mutant androgen receptor proteins expressed in stably transfected $\mathrm{CHO}$ cells. The level of specific $5 \alpha$-dihydrotestosterone binding was assayed in monolayer cultures of $\mathrm{CHO}$ cells stably transfected with the normal or mutant androgen receptor cDNAs. The $B_{\max }$ was derived from Scatchard analysis of data derived from a concentration curve. In separate experiments, we established that the androgen receptor produced in CHO cells transfected with the Gln 12 cDNA demonstrated no thermal instability (data not shown). The values shown are expressed as percent of the level detected in assays performed at $30^{\circ} \mathrm{C}$. The raw $B_{\max }$ values are indicated in parentheses below the individual bars and are expressed as femtomoles of specific dihydrotestosterone binding per milligram of protein. 

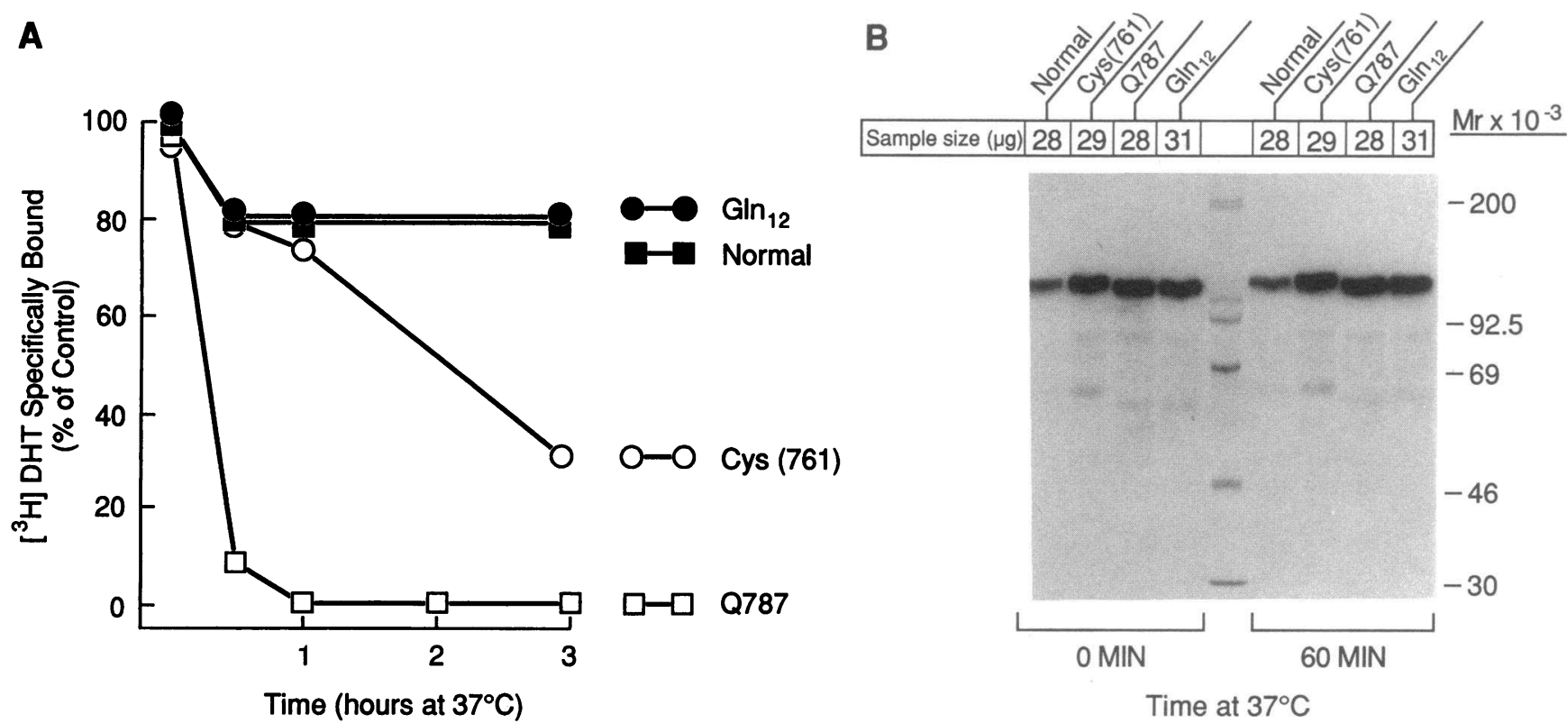

Figure 6. The androgen receptor protein produced after transfection with cDNAs containing both mutations demonstrate thermal instability in a broken cell assay. $(A)$ Cytosolic androgen receptor was prepared from COS cells transfected with cDNAs encoding the normal or mutant androgen receptors. The extracts were labeled by incubation with $3 \mathrm{nM}\left[{ }^{3} \mathrm{H}\right]$ dihydrotestosterone for $4 \mathrm{~h}$ at $4^{\circ} \mathrm{C}$. After labeling, samples were shifted to $37^{\circ} \mathrm{C}$ for $0,0.5,1,2$, or $3 \mathrm{~h}$ and the amount of specific dihydrotestosterone binding determined after incubation with dextran-coated charcoal to remove free $\left[{ }^{3} \mathrm{H}\right]$ dihydrotestosterone. The graphic representation has normalized the amount of specific dihydrotestosterone binding to that present at time zero. (B) Aliquots of the same samples incubated for 0 or $1 \mathrm{~h}$ at $37^{\circ} \mathrm{C}$ depicted in $A$ were analyzed by immunoblotting using an antiserum that recognizes the amino terminus of the human androgen receptor (18). The sample size (in micrograms of protein added) is shown above and the position of the migration of radiolabeled protein markers is shown in the right margin.

cDNA encoding the normal or Gln 12 expression plasmids, converted $53 \%$ or $61 \%$ of $\left[{ }^{14} \mathrm{C}\right]$ chloramphenicol to its acetylated products. By contrast, the tyrosine to cysteine substitution at amino acid 761 (present in plasmid Cys 761) decreases the receptor function to $51 \%$ of that detected for the normal receptor. When both the cysteine 761 mutation and the truncation of the glutamine segment are both present (plasmid
Q787), androgen receptor function is further impaired and exhibits only $7 \%$ of the normal receptor activity.

High androgen concentration can partially overcome the defective androgen receptor predicted for patient $Q 787$. The fact that patient $\mathrm{Q} 787$ responded to therapy with high doses of dihydrotestosterone (7) suggests that high doses of androgen may overcome in part the functional defect in the androgen recep-

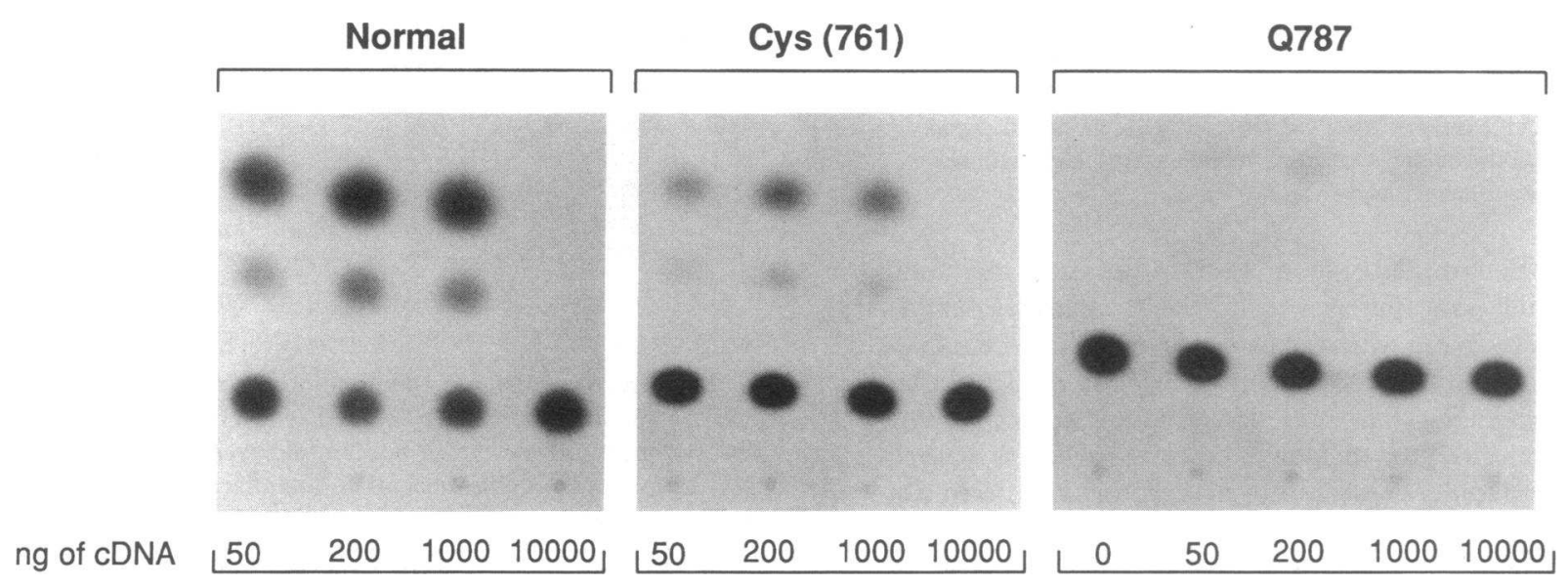

Figure 7. The mutant androgen receptor predicted for patient Q787 is severely impaired in cotransfection assays of receptor function. Cultures of $\mathrm{CV} 1$ cells were transfected with a mixture of the reporter plasmid MMTV-CAT $(10 \mu \mathrm{g})$ and a variable quantity of expression plasmid encoding normal or mutant androgen receptors. After stimulation with $2 \mathrm{nM} 5 \alpha$-dihydrotestosterone for $48 \mathrm{~h}$, cell extracts were prepared and assayed for CAT activity (17). The lack of dose-response when higher levels of androgen receptor cDNA were transfected is presumed to reflect the limiting levels of cellular transcription factors, as has been described for the estrogen receptor (19). 


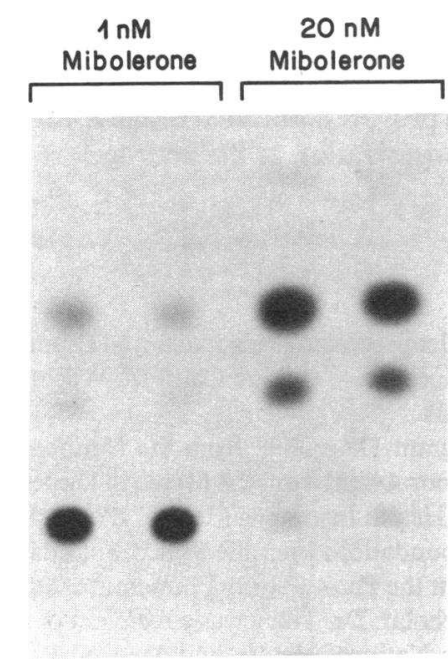

Figure 8. High doses of mibolerone can partially overcome the functional defect of the androgen receptor predicted for patient Q787. Parallel dishes of CV1 cells were transfected with $200 \mathrm{ng}$ of expression vector encoding the androgen receptor predicted for patient Q787 and $10 \mu \mathrm{g}$ of the reporter plasmid MMTV-CAT Parallel cultures were stimulated with either 1 or $20 \mathrm{nM}$ mibolerone for $48 \mathrm{~h}$. Cell extracts were prepared and assayed for CAT activity (17).

tor protein. For this reason, we examined the ability of the mutant androgen receptor predicted for patient Q787 to stimulate the MMTV-CAT reporter gene in response to different concentrations of mibolerone ( 1 and $20 \mathrm{nM}$ ) (Fig. 8). Although low levels of promoter activity could be detected in response to stimulation with $1 \mathrm{nM}$ mibolerone, high doses of mibolerone substantially increased the activation of the MMTV promoter by the mutant receptor.

\section{Discussion}

The analysis of the coding segment of androgen receptor gene in the proband from a family with a qualitative defect in the androgen receptor revealed two alterations. The first is a shortening of the glutamine homopolymeric segment to twelve residues from the 20-22 residues present in most normal controls. The second is a single nucleotide substitution in exon 5 that causes a tyrosine to cysteine substitution.

Variations in the length of the glutamine homopolymeric segment are common among normal individuals. In our analysis of this segment in 12 unrelated individuals (Fig. 9), the

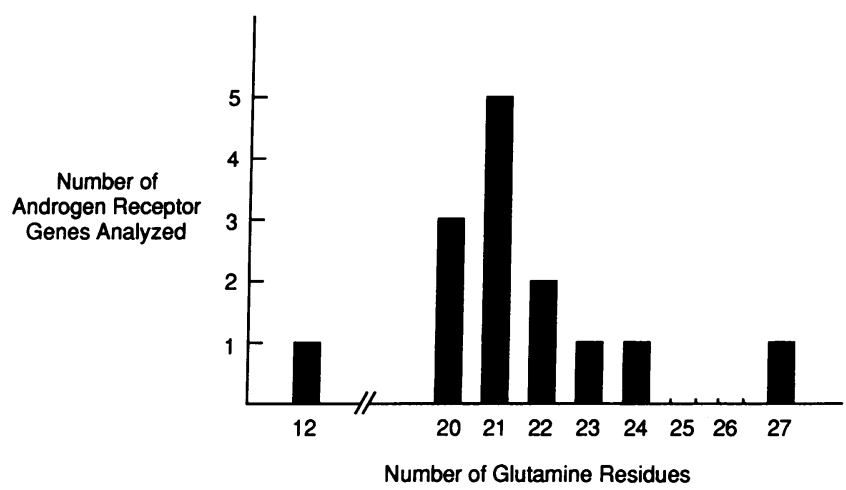

Figure 9. The length of the glutamine homopolymeric segment is heterogenous. The DNA segment containing the glutamine homopolymeric segment (I-2, reference 3 ) was amplified from genomic DNA samples prepared from 14 unrelated individuals. The nucleotide sequence was determined for each sample. The number of androgen receptor genes containing the indicated number of glutamines is indicated. androgen receptor gene contains between 20 and 22 residues in most individuals, although one contains a glutamine homopolymeric segment that encodes 27 glutamine residues. The frequency of this type of polymorphism is far higher than any restriction fragment polymorphism linked to the androgen receptor that has been identified to date $(20,21)$.

We employed the shortening of this segment of the androgen receptor to analyze the inheritance of the mutant receptor gene in this family. As expected, subjects I-1, II-1, II-2, and II-4 are heterozygous carriers of the mutant allele. More importantly, subject III-3 does not carry the abnormal androgen receptor gene and hence is not at risk for transmitting the defect.

We introduced these two alterations into a normal androgen receptor cDNA and studied the physical and functional properties of the proteins in eukaryotic cells after transfection. The single amino acid substitution (tyrosine $\rightarrow$ cysteine at residue 761) is largely responsible for the alteration in dissociation rate previously detected in the receptor assayed in fibroblast cultures from patient Q787 (7). As in previous studies, the enhanced rate of ligand dissociation is not accompanied by a significant change in binding affinity (7). These results suggest that the tyrosine to cysteine substitution does not alter the "fit" of ligand within the hormone-binding pocket of the androgen receptor but affects the capacity of the receptor to be maintained in a form to which ligand is tightly bound. This subtle change in the hormone-binding properties of the mutant receptor is presumably due to the substitution of a different polar uncharged amino acid (cysteine) in place of the normal tyrosine residue at this position.

In $\mathrm{CHO}$ cells stably transfected with cDNAs encoding the normal androgen receptor, the receptor containing 12 glutamine residues and the receptor containing only the tyrosine $\rightarrow$ cysteine substitution demonstrate normal thermal stability. However, transfection of an androgen receptor cDNA containing both mutations leads to the expression of an androgen receptor protein with thermal instability similar to that previously characterized in skin fibroblasts from the proband (7). Similar data were obtained when studies are performed on cytosol prepared from COS cells transfected with the normal and mutant androgen receptor cDNAs. These results suggest that the three-dimensional structure of the androgen receptor must permit portions of the amino terminus to interact with segments of the hormone-binding domain. While this interaction appears normally to stabilize the androgen receptor to thermal denaturation, truncation of the glutamine homopolymeric segment by itself is not sufficient to destabilize the androgen receptor. However, in a mutant androgen receptor in which the hormone-binding domain has been altered by a second mutation (the tyrosine to cysteine substitution at amino acid 761) this effect becomes demonstrable. The effect of the truncation of glutamine-rich segment of the androgen receptor is not limited to the role of the receptor in gene activation as has been described for other members of the steroid receptor family (22-24), because the truncation also has an effect on the physical properties of the transfected receptor protein.

Thermal instability is a qualitative marker of steroid receptor dysfunction in many subjects (25). To date, however, the molecular changes that underlie this phenomenon have not been elucidated. In these studies we have demonstrated that the thermolability in dihydrotestosterone binding of patient Q787 is not accompanied by appreciable changes in the quantity or 
mobility of immunoreactive androgen receptor present. These results imply that warming permits an unfolding of the receptor protein and does not result in detectable changes in the amount or integrity of the androgen receptor protein as assayed by SDS-PAGE and Western analysis.

Cotransfection assays that test the capacity of androgen receptor to activate the MMTV promoter also indicate that androgen receptor molecules that carry both mutations are more severely impaired than those that carry either mutation alone. These results suggest that the thermal lability and enhanced dissociation rate of the mutant androgen receptor are markers of changes in structures that have direct impact on the functional capacity of the receptor molecules.

The mutant androgen receptor predicted for patient Q787 demonstrated $\sim 7 \%$ of normal receptor activity in cotransfection assays. The phenotype of patient $\mathrm{Q} 787$ was male in character and exhibited virilization in response to high-dose testosterone therapy indicating that the defective function of the androgen receptor can be overcome, at least partially, by such therapy (7). In agreement with this expectation, the MMTV promoter was activated to a much higher level by the mutant androgen receptor (Q787) in the presence of $20 \mathrm{nM}$ mibolerone than in the presence of $1 \mathrm{nM}$ mibolerone. These observations have several implications. First, the results imply that the level of function assayed for the androgen receptor predicted for patient Q787 ( 7\% of control) is near a critical level that permits male phenotypic development. Second, high doses of androgen are able to augment the function of the defective receptor and increase its capacity to stimulate target genes. It is not yet clear whether this result is due to an increase in the concentration of androgen receptor (e.g., due to "up-regulation") (26) or because high doses of androgen stabilize a form of the androgen receptor that is able to stimulate the MMTV promoter. This interpretation presumes that the in vitro phenomenon detected using the MMTV-CAT reporter system reflects changes in the activation of androgen responsive genes in vivo that allow virilization of the patient with high dose androgen therapy.

These studies provide several novel insights into the structure of the human androgen receptor. First, a critical residue (tyrosine 761) is crucial to normal ligand binding. Second, this same amino acid substitution affects the thermal stability of the androgen receptor. Third, the thermal instability, the dissociation rate abnormality, and the defective function of the mutant receptor protein can be accentuated by a truncation within the amino terminus. This finding suggests physical interaction of the amino terminus and the hormone binding domain. This effect influences the physical properties of receptor function such as the dissociation of ligand and thus appears to be distinct from effects due to alterations in the amino terminal transactivation domain, as has been described for the estrogen and glucocorticoid receptors $(19,22-24)$.

These studies demonstrate a remarkable correlation between the clinical consequences and the biochemical abnormalities of patient Q787. While several of these results might be anticipated from studies that have defined the functional domains of the glucocorticoid and estrogen receptors (27), analyses of more subtle mutations in androgen receptor function in patients such as patient $\mathrm{Q} 787$ complement results that have been obtained for other naturally occurring mutations in the steroid receptor family, such as the vitamin D receptor (28) and thyroid hormone receptor (29). Analysis of the androgen receptor gene of other patients with qualitative abnormalities of the androgen receptor proteins will provide additional insights into the structural and functional organization of the androgen receptor.

\section{Acknowledgments}

We thank Brenda Hennis for excellent secretarial assistance and Diane Rae Allman for her cell culture expertise. We thank Carol M. Wilson for performing the Western analysis.

This work was supported by grant DK-03892 from the National Institutes of Health, a Basil O'Connor Award from the March of Dimes (No. 5-694), the Medical Life and Health Insurance Medical Research Fund, the Charles E. Culpeper Foundation, Inc., the Welch Foundation (No. I-1090), and a grant from the Perot Family Foundation. Dr. McPhaul is a Culpeper Medical Scholar. Dr. Tilley was a recipient of a C. J. Martin Fellowship from the National Health and Medical Research Council of Australia.

\section{References}

1. Griffin, J. E., and J. D. Wilson. 1989. The androgen resistance syndromes: $5 \alpha$-reductase deficiency, testicular feminization, and related syndromes. In The Metabolic Basis of Inherited Disease, 6th edition. C. R. Scriver, A. L. Beaudet, W. S. Sly, and D. Valle, editors. McGraw-Hill Book Co., Inc., New York. 19191944.

2. Marcelli, M., W. D. Tilley, C. M. Wilson, J. D. Wilson, J. E. Griffin, and M. J. McPhaul. 1990. A single nucleotide substitution introduces a premature termination codon into the androgen receptor gene of a patient with receptornegative androgen resistance. $J$. Clin. Invest. 85:1522-1528.

3. Marcelli, M., W. D. Tilley, J. E. Griffin, J. D. Wilson, and M. J. McPhaul 1990. Definition of the human androgen receptor gene structure permits the identification of mutations that cause androgen resistance: premature termination of the receptor protein at amino acid residue 588 causes complete androgen resistance. Mol. Endocrinol. 4:1105-1116.

4. Lubahn, D. B., T. R. Brown, J. A. Simental, H. N. Higgs, C. J. Migeon, E. M. Wilson, and F. S. French. 1989. Sequence of the intron/exon junctions of the coding region of the human androgen receptor gene and identification of a point mutation in a family with complete androgen insensitivity. Proc. Natl. Acad. Sci. USA. 86:9534-9538.

5. Sai, T., S. Seino, C. Chang, M. Trifiro, L. Pinsky, A. Mhatre, M. Kaufman, B. Lambert, J. Trapman, A. O. Brinkmann, et al. 1990. An exonic point mutation of the androgen receptor gene in a patient with complete androgen insensitivity. Am. J. Hum. Genet. 46:1095-1100.

6. Brown, T. R., D. B. Lubahn, E. M. Wilson, D. R. Joseph, F. W. French, and C. J. Migeon. 1988. Deletion of the steroid-binding domain of the human androgen receptor gene in one family with complete androgen insensitivity syndrome: evidence for further genetic heterogeneity in this syndrome. Proc. Natl. Acad. Sci. USA 85:8151-8155.

7. Grino, P. B., R. F. Isidro-Gutierrez, J. E. Griffin, and J. D. Wilson. 1989 Androgen resistance associated with a qualitative abnormality of the androgen receptor and responsive to high dose androgen therapy. J. Clin. Endocrinol. Me tab. 68:578-584.

8. Chirgwin, J. M., A. E. Przybla, R. J. McDonald, and W. J. Rutter. 1979. Isolation of biologically active ribonucleic acid from sources enriched in ribonuclease. Biochemistry. 18:5294-5299.

9. Saiki, R. K., D. H. Gelfand, S. Stoffel, S. J. Scharf, R. Higuchi, G. T. Horn, K. B. Mulus, and H. A. Erlich. 1988. Primer directed enzymatic amplification of DNA with a thermostable DNA polymerase. Science (Wash. DC). 239:487-491.

10. Kaiser, K., and N. E. Murray. 1985. The use of phage lambda replacement vectors in the construction of representative genomic DNA libraries. In DNA Cloning, Vol. I. D. M. Glover, editor. IRL Press, Washington, DC. 1-47.

11. Sanger, F., A. R. Carlson, B. G. Barrell, A. J. H. Smith, and B. A. Roe. 1980. Cloning in single-stranded bacteriophage as an aid to rapid DNA sequencing. J. Mol. Biol. 143:161-178.

12. Tilley, W. D., M. Marcelli, J. D. Wilson, and M. J. McPhaul. 1989. Characterization and expression of a cDNA encoding the human androgen receptor. Proc. Natl. Acad. Sci. USA. 86:327-331.

13. Graham, F. L., and A. J. Vander Eb. 1973. A new technique for the assay of infectivity of human adenovirus 5 DNA. Virology. 52:456-467.

14. Southern, P. J., and P. Berg. 1982. Transformation of mammalian cells to antibiotic resistance with a bacterial gene under control of the SV40 early region promoter. J. Mol. Appl. Genet. 1:327-341. 
15. Griffin, J. E., and J. D. Wilson. 1977. Studies on the pathogenesis of the incomplete forms of androgen resistance in man. J. Clin. Endocrinol. Metab. 45:1137-1143.

16. Giguère, V., S. M. Hollenberg, M. G. Rosenfeld, and R. M. Evans. 1986 Functional domains of the human glucocorticoid receptor. Cell. 46:645-652.

17. Gorman, C. M., L. F. Moffat, and B. H. Havard. 1982. Recombinan genomes which express chloramphenicol acetyl transferase in mammalian cells. Mol. Cell. Biol. 2:1044-1051.

18. Husmann, D. A., C. M. Wilson, M. J. McPhaul, W. D. Tilley, and J. D. Wilson. 1990. Antipeptide antibodies to two distinct regions of the androgen receptor localize the receptor protein to the nuclei of target cells in the rat and human prostate. Endocrinology. 126:2359-2368.

19. Bocquel, M. T. V. Kumar, C. Stricker, P. Chambon, and H. Gronemeyer. 1989. The contribution of the $\mathrm{N}$ - and C-terminal regions of steroid receptors to activation of transcription is both receptor and cell-specific. Nucleic Acids Res. 17:2581-2959.

20. Brown, C. J., S. J. Goss, D. B. Lubahn, D. R. Joseph, E. M. Wilson, F. S. French, and H. F. Willard. 1989. Androgen receptor locus on the human X chromosome: regional localization of Xq11-12 and description of a DNA polymorphism. Am. J. Hum. Genet. 44:264-269.

21. Wieacker, P., J. E. Griffin, T. Wienker, J. M. Lopez, J. D. Wilson, and M. Breckwoldt. 1987. Linkage analysis with RFLPs in families with androgen resistance syndromes: Evidence for close linkage between the androgen receptor locus and the DXS1 segment. Hum. Genet. 76:248-252.
22. Godowski, P. J., D. Picard, and K. R. Yamamoto. 1988. Signal transduction and transcriptional regulation by glucocorticoid receptor-Lex A fusion proteins. Science (Wash. DC). 241:812-816.

23. Webster, N. J. G., S. Green, D. Tasset, M. M. Pongilikit, and P. Chambon. 1989. The transcriptional activation function located in the hormone-binding domain of the human oestrogen receptor is not encoded in a single exon. $E M B O$ (Eur. Mol. Biol. Organ.) J. 8:1441-1446.

24. Lees, J. A., S. E. Fawell, and M. G. Parker. 1989. Identification of two transactivation domains in the mouse oestrogen receptor. Nucleic Acids Res. 17:5477-5488.

25. Griffin, J. E. 1979. Testicular feminization associated with a thermolabile androgen receptor in cultured human fibroblasts. J. Clin. Invest. 64:1624-1631.

26. Kaufman, M., L. Pinsky, and R. Feder-Hollander. 1981. Defective up-regulation of the androgen receptor in human androgen insensitivity. Nature (Lond.). 293:735-737.

27. Evans, R. M. 1988. The steroid and thyroid hormone receptor superfamily. Science (Wash. DC). 240:889-895.

28. Feldman, D., and P. J. Malloy. 1990. Hereditary 1,25 dihydroxyvitamin $D$ resistant rickets: molecular basis and implications for the role of $1,25(\mathrm{OH})_{2} \mathrm{D}_{3}$ in normal physiology. Mol. Cell. Endocrinol. 72:C57-62.

29. Sakurai, A., K. Takeda, K. Ain, P. Ceccarelli, A. Nakai, S. Seino, G. I. Bell, S. Refetoff, and L. de Groot. 1989. Generalized resistance to thyroid hormone associated with a mutation in the ligand-binding domain of the human thyroid hormone receptor $\beta$. Proc. Natl. Acad. Sci. USA. 86:8977-8981. 